\title{
Effectiveness of keyword versus direct instruction on vocabulary acquisition by primary-grade handicapped learners
}

\author{
ILISSA PEARLMAN \\ Case Western Reserve University, Cleveland, Ohio
}

(Robert L. Greene, Sponsor)

\begin{abstract}
In this study, the effectiveness of the keyword mnemonic method was compared with that of the direct instruction method for teaching vocabulary words to fourth through sixth graders. Subjects were developmentally handicapped, learning disabled, or mentally retarded, aged 124 to 167 months. Acquisition of vocabulary words was measured by definition, sentence interpretation, and forced-choice questions. Results suggest that the keyword strategy may be too difficult for primary-grade handicapped learners to use.
\end{abstract}

In many studies, it has been found that mnemonic strategies enhance the learning and memory performance of normal, gifted, and handicapped students. One such strategy is an adaptation of Atkinson's (1975) keyword method, originally used to facilitate college students' learning of Russian vocabulary. The keyword method involves three steps. First, the content to be learned is recoded into a keyword that sounds like the word to be learned. For instance, Scruggs, Mastropieri, and Levin (1985) recoded the vocabulary word ranid to the keyword rain. Second, the learner sees an interactive picture relating the new word to the keyword. Thus, "ranid" (which means frog) was depicted by Scruggs et al. (1985) as a frog sitting in the rain. Finally, the learner is taught to retrieve the definition after thinking of the keyword and recalling the interactive picture.

The keyword method's superiority over direct (nonmnemonic) instruction has been demonstrated in teaching science facts to mentally retarded (MR) and learning disabled (LD) adolescents (e.g., see Mastropieri, Scruggs, \& Levin, 1986; Scruggs, Mastropieri, McLoone, Levin, \& Morrison, 1987), improving eighth graders' prose comprehension (Peters, Levin, McGivern, \& Pressley, 1985), and teaching vocabulary words to educable mentally retarded (EMR) junior high school students (Scruggs et al., 1985) and LD sixth graders (Condus, Marshall, \& Miller, 1986). In a review of cognitive strategies for poor learners, Pressley, Johnson, and Symons (1987) con-

\footnotetext{
The subjects in this experiment came from a larger sample used in a study by Short, Evans, Friebert, and Schatschneider (1989). I am very grateful to Robert Greene, Elizabeth Short, and Jane Kessler for their help with this research. I thank Thomas Scruggs, Margo Mastropieri, and Joel Levin for their suggestions, which helped me to design this study. Requests for reprints should be addressed to Ilissa Pearlman, Department of Psychology, Case Western Reserve University, Cleveland, $\mathrm{OH} 44106$.
}

clude that the keyword strategy's success is robust, since no population has been identified that does not benefit from keyword interventions.

In contrast to keyword pictures, representational pictures display the content to be learned without the use of a keyword. For instance, a representational picture of ranid would depict a frog. Researchers often teach material by using representational images along with a "direct instruction" approach (Becker, Engelmann, Carnine, \& Maggs, 1982), which emphasizes verbal rehearsal, fastpaced questioning and feedback, and frequent learner responding.

The present study's main aim was to investigate the relative effectiveness of the keyword and direct instruction approaches in facilitating primary-grade handicapped learners' memories of vocabulary words. Previous studies have demonstrated that the keyword strategy is more effective than direct instruction in teaching vocabulary words to EMR junior high school students (Scruggs et al., 1985) and LD sixth graders (Condus et al., 1986). However, questions remained about whether the keyword strategy could be successfully extended downward, to a lower functioning population of primary-grade students.

To test whether mnemonic instruction would prove superior to direct instruction for primary-grade handicapped learners, as it had for cognitively impaired adolescents, the procedure in the present study partially replicated that used by Scruggs et al. (1985) to teach vocabulary words to EMR junior high school students. In the Scruggs et al. (1985) study, students were randomly assigned to two groups. One group learned the first set of vocabulary words through the keyword procedure and the second set through the direct instruction method; the other group learned the two vocabulary sets in the reverse order. After instruction, the students were asked the meaning of each word. Definition recall was $50 \%$ better in the mnemonic than in the direct instruction condition. 


\section{METHOD}

\section{Subjects}

The present study was conducted at an elementary school in a middleclass suburb of a medium-sized midwestern city. Sixteen students in three special education classrooms served as subjects. Based on IQ and achievement test scores, all the students were developmentally handicapped (IQ scores of 70-85 and no significant IQ-achievement discrepancy), LD, or MR (according to federal, state, and local criteria).

The students, who were in Grades 4 to 6, ranged in age from 124 to 167 months, with a mean age of 141.38 months $(S D=11.97)$. The students' IQ scores on the Peabody Picture Vocabulary Test-Revised (PPVT-R; Dunn \& Dunn, 1981) ranged from 40 to 87 ( $M=67.13$; $S D=15.03$ ). Eight of the subjects were male, and 8 subjects were female.

\section{Materials}

Sixteen "survival skills" vocabulary words, including two examples, were selected by the experimenter in consultation with classroom teachers. The teachers felt that (1) the students did not know the meanings of the selected words, and (2) understanding the chosen words might be important for the students' safety. One might encounter such words on a medicine bottle (e.g., avoid; external; physician) or on a container of a toxic substance (e.g., warning; ventilation; flammable).

The vocabulary words were divided into two sets of seven words each. For each set of words, both keyword (mnemonic) and direct instruction pictures were designed.

Mnemonic instruction condition. Keyword pictures were drawn on $8.5 \times 11$ in. cards. Each card contained an interactive picture of the keyword and the vocabulary word's meaning.

Direct instruction condition. Pictures were drawn on $8.5 \times 11$ in. cards. Each card contained a picture of the vocabulary word's meaning. The pictures were the same as in the mnemonic condition, except that the keyword was not depicted.

\section{Procedure}

All students were seen by the experimenter in a quiet room in the students' school. The students were told that they would learn some vocabulary words and then receive a short quiz on the words. A crossover design was employed, whereby all students were assigned randomly to two groups. One group was taught the first word list with the mnemonic procedure and the second word list with the direct instruction procedure, and the other group was taught the first list with the direct instruction and the second word list with the mnemonic procedure.

Mnemonic instruction condition. Each student was first taught the keywords for the two sample items. Then the keyword strategy was explained while the interactive pictures were shown for the sample items. The student was next given a practice quiz on the two example words. After that, each student was taught the keywords for the seven target items. Following keyword instruction, the experimenter read the word list and tested the student's recall of all the keywords.

Next, the experimenter presented and explained each interactive picture for 1 min (e.g., "The word clue for pharmacy is farmer, and pharmacy means drugstore. Remember this picture of a farmer in the drugstore. That's how you can remember that pharmacy means drugstore" ). After the seventh word was presented, the experimenter reminded the student to follow the retrieval steps, and the vocabulary test was administered. The vocabulary test had three parts. First, the students were asked to define each word. Next, they were asked to explain a sentence read to them that contained the word (e.g., "Your mom tells you she is going to the pharmacy. Where is she going?"'). Finally, the students were given a forced-choice measure (e.g., "Your mom tells you she is going to the pharmacy. Is she: (a) going to the drugstore, or (b) going to the doctor's office?'). The students' responses on the first two parts were audio recorded, and their replies on the third part were circled on a form.

Direct instruction condition. In this condition, each student was taught the seven vocabulary words, using a direct instruction procedure similar to that used by Scruggs et al. (1985). Sample items were taught first, by showing the students a picture of each sample item while the word was defined. The students then received a practice quiz on the sample words. Next, the seven words were taught by showing students each picture for 1 min while the word was defined. After all the words had been taught, each picture was briefly reviewed, which replaced the time used to teach the keywords in the mnemonic condition. Finally, the threepart test also used in the mnemonic condition was administered.

The total amount of time spent for instruction and testing was approximately 16 min per subject in the direct instruction condition and $18 \mathrm{~min}$ in the mnemonic condition.

\section{Scoring}

Student audiotaped responses to the first two parts of the quiz were scored by a Psychology Department faculty member who was blind to the conditions to which the students were assigned. A correct response or a close synonym was assigned one point (e.g., "Irritate bothers you"). Blatantly incorrect responses, omissions, and responses that referred to the keyword rather than the definition, despite probes from the examiner ("Tell me more about it"), received zero points (e.g., "Irritate means ear." [probe] "Like if somebody's hollering in your ear"). Correct responses to the third part were assigned one point.

\section{RESULTS}

A significant difference between the mnemonic and direct instruction conditions was found on the definition measure $[F(1,15)=5.997, p<.05]$. An examination of the means revealed that the subjects correctly defined more words when taught by the direct instruction $(M=5.25)$ than by the mnemonic $(M=4.06)$ method. There were no significant between-groups differences on the other two measures. On the sentence interpretation measure, the mean was 4.44 for the direct instruction group and 4.56 for the mnemonic group. On the forcedchoice measure, the means were 6.19 and 6.44 for the direct instruction and mnemonic conditions, respectively.

\section{DISCUSSION}

In summary, the present study did not reveal the keyword strategy to be superior to direct instruction in teaching vocabulary words to primary-grade handicapped learners. In fact, the definition performance measure showed that the subjects remembered significantly more vocabulary word meanings when taught by the direct instruction rather than the keyword method. This finding is contrary to the findings of earlier studies in which the two strategies were compared.

Differences in method, words, scoring, and materials may partly account for the divergent findings. For instance, the present study did not include vocabulary words, keywords, or definitions printed on the picture cards, since it was felt that poor readers would be distracted by trying to decode the words. However, in the Scruggs et al. (1985) study, words printed on the cards may have helped students to understand the keyword strategy.

Another difference is that the vocabulary words used by Scruggs et al. (1985) are less frequently used, and probably less familiar, than the present study's words. Also, in the present study, more time was allocated to teach the words. More familiar words and a longer training period may have facilitated the use of rehearsal, so that words were learned better in the direct instruction condition. In addition, Scruggs et al.'s (1985) words may have lent themselves more readily to keywords than the present study's words did.

However, the most obvious explanation for the findings in the present study is that the three-step keyword strategy simply is too complex for cognitively impaired elementary school students. During testing, several students substituted the keyword for the word's definition-for instance, by defining fever as "beaver." Moreover, during training, the students were often confused about how to use the keyword strategy. Student responses indicated that primary-grade handicapped learners are cognitively unable to differentiate relevant (definition) from irrelevant (keyword) information. 
In conclusion, the keyword strategy appears to be a promising educational approach for many populations. However, the keyword approach appears to be too difficult for primary-grade handicapped learners. Future research should investigate the keyword strategy's effectiveness with other populations, and with other cognitive tasks.

\section{REFERENCES}

Atkinson, R. C. (1975). Mnemotechnics in second-language learning. American Psychologist, 30, 821-828.

Becker, W. C., Engelmann, S., Carnine, D. W., \& Maggs, A. (1982). Direct instruction technology: Making learning happen. In P. Karoly \& J. J. Steffen (Eds.), Improving children's competence: Advances in child behavioral analysis and therapy (Vol. 1, pp. 151204). Lexington, MA: Heath.

Condus, M. M., Marshall, K. J., \& Miller, S. R. (1986). Effects of the keyword mnemonic strategy on vocabulary acquisition and maintenance by learning disabled children. Journal of Learning Disabilities, 19, 609-613.

Dunn, L. M., \& Dunn, L. (1981). Peabody Picture Vocabulary Test (rev. ed.). Circle Pines, MN: American Guidance Service.
Mastropieri, M. A., Scruggs, T. E., \& Levin, J. R. (1986). Direct vs. mnemonic instruction: Relative benefits for exceptional learners. Journal of Special Education, 20, 299-308.

Peters, E. E., Levin, J. R., McGivern, J., \& Pressley, M. (1985). Further comparison of representational and transformational proselearning imagery. Journal of Educational Psychology, 77, 129-136.

Pressley, M., Johnson, C. J., \& Symons, S. (1987). Elaborating to learn and learning to elaborate. Journal of Learning Disabilities, 20 , 76-91.

SCRUGgs, T. E., MASTropieri, M. A., \& LeVin, J. R. (1985). Vocabulary acquisition by mentally retarded students under direct and mnemonic instruction. American Journal of Mental Deficiency, 89, 546-551.

SCruggs, T. E., Mastropieri, M. A., McLoone, B. B., Levin, J. R., \& Morrison, C. R. (1987). Mnemonic facilitation of learning disabled students' memory for expository prose. Journal of Educational Psychology, 79, 27-34.

Short, E. J., Evans, S. W., Friebert, S. E., \& Schatschneider, C. W. (1989). Thinking aloud during problem-solving: Facilitation effects. Manuscript submitted for publication.

(Manuscript received July 8, 1989.) 